\title{
Clinical experience with plerixafor as a mobilization regimen for autologous peripheral blood stem cell transplantation in patients with refractory germ cell tumors
}

\author{
IGNACIO GARCÍA-ESCOBAR ${ }^{1}$, LUCÍA PARRILLA ${ }^{1}$, LAURA MONTEJANO ORTEGA ${ }^{2}$, \\ DANIEL CASTELLANOS ${ }^{1}$, MARÍA ÁNGELES MONTALBÁN PALLARÉS ${ }^{1}$ and HERNÁN CORTÉS-FUNÉS ${ }^{1}$ \\ Departments of ${ }^{1}$ Medical Oncology and ${ }^{2}$ Hematology and Hemotherapy, \\ University Hospital 12 de Octubre, 28041 Madrid, Spain
}

Received December 4, 2013; Accepted February 18, 2014

DOI: $10.3892 / \mathrm{mco} .2014 .362$

\begin{abstract}
The purpose of this study was to report our experience with administration of plerixafor for the mobilization of hematopoietic stem cells (HSCs) in patients with refractory or recurrent germ cell tumors who were candidates for salvage therapy with high-dose chemotherapy and HSC transplantation and for whom mobilization of HSCs had not been achieved by standard therapies. This retrospective and observational study selected patients who were eligible for autologous HSC transplantation (AHSCT) and received plerixafor after failure of HSC mobilization by granulocyte colony-stimulating factor (G-CSF). A total of 5 patients (4 male and 1 female), aged $19-41$ years (mean age, 29.6 years) were initially selected. Four patients (80\%) achieved an adequate HSC mobilization with plerixafor and subsequently received high-dose chemotherapy followed by HSC transplantation. In these patients, the number of $\mathrm{CD} 34^{+}$cells collected following plerixafor mobilization was $1.8 \times 10^{6}-10.3 \times 10^{6}$ cells $/ \mathrm{kg}$, with a peak $\mathrm{CD} 34^{+}$cell count of 7.0-32.0 cells $/ \mu 1$. Following HSC infusion, these 4 patients achieved a neutrophil count of $>0.5 \times 10^{3} / \mathrm{mm}^{3}$ and a platelet count of $>20,000 / \mu \mathrm{l}$ between days 10 and 14 . Therefore, patients with high-risk germ cell tumors eligible for AHSCT who are refractory to mobilization by G-CSF, may benefit from the use of plerixafor, possibly to the same extent as patients with lymphoma and multiple myeloma.
\end{abstract}

\section{Introduction}

Germ cell tumors are chemosensitive and potentially curable neoplasms, even in cases with advanced stage or metastatic

Correspondence to: Dr Ignacio García-Escobar, Department of Medical Oncology, University Hospital 12 de Octubre, s/n Avenue Córdoba, 28041 Madrid, Spain

E-mail: naxto@hotmail.com

Key words: hematopoietic stem cell transplantation, mobilization strategies, mobilization failure, plerixafor disease (1-4). Patients with refractory disease or those exhibiting disease progression after different lines of treatment may be considered eligible for salvage therapy. Some patients may undergo surgical treatment; however, for those patients who are not candidates for surgery, a viable therapeutic option is to receive high-dose chemotherapy followed by autologous hematopoietic stem cell transplantation (AHSCT). To perform an AHSCT, at least $2 \times 10^{6} \mathrm{CD} 34^{+}$cells $/ \mathrm{kg}$ must be collected prior to treatment (5). Mobilization of hematopoietic stem cells (HSCs) into the peripheral blood is usually performed by the administration of granulocyte colony-stimulating factor (G-CSF). However, failure to mobilize HSCs occurs in 20-30\% of patients, usually those who have previously received large and cumulative doses of chemotherapy (6). It was demonstrated that the number of prior treatments of chemotherapy with alkylating agents or platinum is correlated with failure of mobilization of HSCs (7). Therefore, new strategies have been developed to achieve an appropriate mobilization of HSCs in this group of patients.

Plerixafor (AMD3100, Mozobil ${ }^{\circledR}$, Sanofi, Paris, France) is a reversible chemokine receptor type 4 (CXCR4) antagonist that inhibits CXCR4 in CD34 ${ }^{+}$cells and blocks the binding of its cognate ligand, stromal cell-derived factor $1 \alpha$ (SDF-1 $\alpha$; CXCL12), to the bone marrow compartment. CXCL12 is expressed in the stroma of the bone marrow (6), causing a rapid mobilization of stem cells from the bone marrow into the peripheral blood. Following the results of previous phase III multicenter studies $(6,8,9)$, plerixafor in combination with G-CSF was approved by the European Medicines Agency (EMA) and the United States Food and Drug Administration (FDA) to enhance mobilization of HSCs into the peripheral blood for subsequent cell collection and AHSCT in patients with lymphoma and multiple myeloma. However, although several studies have been conducted to establish the role of plerixafor in hematological tumors, the number of studies investigating the role of plerixafor in patients with solid tumors and prior failure of HSC mobilization is currently limited.

The aim of this retrospective analysis was to report our experience with plerixafor for the mobilization of HSCs in patients with refractory or recurrent germ cell tumors. The patients included in this analysis were candidates for salvage 
Table I. Baseline characteristics of the selected patients.

Patient no.

\begin{tabular}{lccccc}
\cline { 2 - 5 } Characteristics & 1 & 2 & 3 & 4 & 5 \\
\hline Age (years) & 19 & 24 & 31 & 41 & 33 \\
Gender & Female & Male & Male & Male & Male \\
Disease & Ovarian dysgerminoma & NSGCT & NSGCT & NSGCT & NSGCT \\
Stage at inclusion & IIIC & IIIC & IIIC & IIIC & IB \\
Prior radiation therapy & No & No & No & No & No \\
No. of previous therapy lines & 1 & 1 & 2 & 1 & 2 \\
Prior therapy regimens & BEP x 5 & BEP x 4 & BEP x 4 & PIE x 3 & BEP x 4 \\
& TIP x 4 & TIP x 4 & EP x 1 & PIE-bleomycin x 3 & TIP x 4 \\
No. of cisplatin-containing cycles & 5 & & TIP x 4 & TIP x 3 & 8 \\
\hline
\end{tabular}

BEP, bleomycin , etoposide and cisplatin; EP, etoposide and cisplatin; NSGCT, non-seminomatous testicular germ-cell cancer; PIE, cisplatin, ifosfamide with mesna and etoposide; TIP, paclitaxel, ifosfamide and cisplatin.

therapy with high-dose chemotherapy and HSC transplantation, since mobilization was not achieved by standard methods.

\section{Patients and methods}

Study design and selection of patients. This was a retrospective analysis of 5 patients treated in the University Hospital 12 de Octubre (Madrid, Spain) between 2009 and 2012. The patients were aged 18-75 years, were diagnosed with refractory germ cell tumors and were candidates for AHSCT. All the patients included in this study received plerixafor after failure of HSC mobilization with G-CSF at doses of $10 \mathrm{mg} / \mathrm{kg}$ once a day or $5 \mathrm{mg} / \mathrm{kg}$ twice a day plus chemotherapy. The high-dose chemotherapy schedule consisted of paclitaxel, ifosfamide and cisplatin and was administered after the mobilization regimen. The follow-up period was 24 months.

This study was conducted in accordance with the Helsinki Declaration of the World Medical Association, amended in 1975 and subsequent revisions, and the International Guidelines for Ethical Review in Epidemiological Studies.

Administration of study treatment. Plerixafor was administered 6-10 $\mathrm{h}$ prior to the apheresis procedure, which was performed when the peripheral $\mathrm{CD} 34^{+}$cell count exceeded 7 cells $/ \mu$ l. The dose of plerixafor administered to the patients was $0.24 \mathrm{mg} / \mathrm{kg}$ subcutaneously. Following the first administration of plerixafor, the procedure continued the next morning with the administration of the corresponding G-CSF dose prior to the apheresis. The administration of plerixafor was repeated for a maximum of 4 days or until the total count of $\mathrm{CD} 4^{+}$cells collected was at least $2 \times 10^{6}$ cells $/ \mathrm{kg}$.

Other study procedures. The total count of $\mathrm{CD} 34^{+}$cells was performed in the flow cytometry laboratory of our hospital, using the protocol of the International Society for Hematotherapy and Graft Engineering. The drug toxicities were monitored and recorded from the time of drug administration until completion of the apheresis procedure, which was performed on a COBE ${ }^{\circledR}$ Spectra $^{\mathrm{TM}}$ Apheresis System.

\section{Results}

Baseline patient characteristics. In total, 5 patients (4 male and 1 female) aged 19-41 years (mean age, 29.6 years) were administered plerixafor. All the patients were diagnosed with non-seminomatous germ cell tumors. Four patients had stage IIIC and 1 had stage IB disease, according to the American Joint Committee on Cancer classification. The detailed baseline patient characteristics are presented in Table I.

Of the 5 patients, 4 had previously received two lines of chemotherapy treatment $(80 \%)$ and 1 patient had received three lines of treatment. The number of previous cycles of platinum-based chemotherapy ranged between 8 and 9, with a mean of 8.6 cycles. The average cumulative dose of platinum was $767 \mathrm{mg}$ (range, 400-830 mg). Four patients achieved a complete response by marker levels and exhibited a residual mass on computed tomography (CT) scan after receiving AHSCT, whereas 1 patient exhibited high marker levels and a residual mass on $\mathrm{CT}$.

Efficacy and safety. Of the 5 patients, 4 (80\%) achieved an adequate HSC mobilization, as determined by the number of $\mathrm{CD}^{+} 4^{+}$cells collected following plerixafor treatment, which was $1.8 \times 10^{6}-10.3 \times 10^{6}$ cells $/ \mathrm{kg}$. The average $\mathrm{CD} 34^{+}$cell count peak increased from 2.6 cells $/ \mu 1$ (range, $1.7-4.8$ cells $/ \mu 1$ ) without plerixafor to 15.3 cells $/ \mu 1$ (range, $7.0-32.0$ cells $/ \mu \mathrm{l}$ ) with plerixafor. The peaks of $\mathrm{CD} 34^{+}$cells with and without administration of plerixafor are presented in Table II. The patient who did not achieve HSC mobilization received plerixafor for only 2 days before the treatment had to be discontinued, due to a reduction in the $\mathrm{CD}_{3} 4^{+}$cell count. Leukapheresis was not attempted in this patient due to the insufficient number of circulating $\mathrm{CD} 34^{+}$cells $/ \mu 1$ in the peripheral blood following treatment.

There were no adverse effects associated with the administration of plerixafor. When the mobilization of HSCs 
Table II. Data on mobilization of HSC and transplantation in the patients of this study.

Patient no.

\begin{tabular}{lccccc}
\cline { 2 - 6 } Variables & 1 & 2 & 3 & 4 & 5 \\
\hline Prior mobilization regimen & TIP + G-CSF & TIP + G-CSF & TIP + G-CSF & TIP + G-CSF & TIP + G-CSF \\
Mobilization with plerixafor & TIP + G-CSF & TIP + G-CSF & TIP + G-CSF & TIP + G-CSF & TIP + G-CSF \\
Successful & Yes & Yes & Yes & No & Yes \\
Collected CD34+ without plerixafor (cells $/ \mathrm{kg}$ ) & $0.8 \times 10^{6}$ & $0.7 \times 10^{6}$ & $0.9 \times 10^{6}$ & NA & $0.3 \times 10^{6}$ \\
Collected CD34+ with plerixafor (cells $/ \mathrm{kg}$ ) & $3.9 \times 10^{6}$ & $3.0 \times 10^{6}$ & $10.3 \times 10^{6}$ & NA & $1.8 \times 10^{6}$ \\
Peak CD34 count without plerixafor (cells $/ \mu \mathrm{l})$ & 2.0 & 1.7 & 2.3 & 2.3 & 4.8 \\
Peak CD34 $4^{+}$count with plerixafor (cells $\left./ \mu \mathrm{l}\right)$ & 14.0 & 8.3 & 32.0 & 0.0 & 7.0 \\
No. of days of apheresis & 4 & 3 & 2 & 2 & 4 \\
AHSCT performed & Yes & Yes & Yes & No & Yes \\
Leukocyte engraftment (days) & 10 & 11 & 9 & No & 11 \\
Platelet engraftment (days) & 12 & 13 & 12 & No & 12 \\
\hline
\end{tabular}

AHSCT, autologous hematopoietic stem cell transplantation; G-CSF, granulocyte colony-stimulating factor; HSC, hematopoietic stem cells; NA, not applicable; TIP, paclitaxel, ifosfamide and cisplatin.

was initiated, the patients achieved a complete recovery after the final chemotherapy cycle, with a neutrophil count of $>1,000$ cells $/ \mu 1$ and a platelet count of $>75,000$ cells $/ \mu 1$.

AHSCT. The 4 patients who achieved sufficient $\mathrm{CD} 4^{+}$cell mobilization received high-dose chemotherapy with stem cell support. These patients underwent 2 AHSCTs with a conditioning regimen consisting of paclitaxel $\left(375 \mathrm{mg} / \mathrm{m}^{2}\right.$ on day 6) plus carboplatin (area under the curve 20) and etoposide $\left(1,500 \mathrm{mg} / \mathrm{m}^{2}\right)$. The carboplatin and etoposide total dose was divided into 6 parts and administered every 12 h over 3 days. The stem cells were reinfused on day 6 of the treatment. The detailed data of the hematological recovery of the study patients are presented in Table II. All the patients who underwent AHSCT achieved a neutrophil count of $>0.5 \times 10^{3}$ cells $/ \mathrm{mm}^{3}$ and a platelet count of $>20.000$ cells $/ \mu 1$ between days 10 and 14 after the HSC infusion. The average time for the neutrophil and platelet count recovery in these patients was 10.25 and 12.5 days, respectively.

\section{Discussion}

AHSCT is a well-established therapeutic option for the treatment of patients with refractory germ cell tumors and is recommended in various guidelines of large cooperative groups, including the Spanish Society of Medical Oncology (10). We performed a retrospective analysis of 5 patients diagnosed with high-risk advanced germ cell tumors who were candidates for high-dose chemotherapy followed by AHSCT. These patients received plerixafor due to a previously poor response to $\mathrm{CD}_{3} 4^{+}$cell mobilization with G-CSFs. Plerixafor has been approved by the FDA and the EMA for HSC mobilization in patients with lymphoma and multiple myeloma. When plerixafor was added to the treatment of these patients, a sufficient mobilization of HSCs into the peripheral blood was achieved in 4 of the 5 patients, with no significant side effects, followed by successful AHSCT in these 4 patients.
AHSCT remains a controversial procedure in patients diagnosed with solid tumors; however, its role is well-established in patients diagnosed with refractory germ cell tumors who have not benefited from standard chemotherapy following relapse or progression and in patients who have not responded to multiple lines of chemotherapy treatment, including regimens with platinum, taxanes and etoposide. Several authors reported the results of retrospective case series demonstrating the benefits of AHSCT regarding tumor response and subsequent disease prognosis $(2,11,12)$, with encouraging results in terms of progression-free and overall survival. The currently available data indicate that, following initial conditioning with high doses of carboplatin and etoposide, followed by paclitaxel or ifosfamide and subsequent HSC infusion, the complete remission rates are $\sim 50 \%$ (13).

In patients with lymphoma, plerixafor was shown to increase the numbers of $\mathrm{CD} 34^{+}$cells in the blood. In fact, this level of mobilization is even observed in poor mobilizers, with an average harvest of $4.7 \times 10^{6}$ cells $/ \mathrm{kg}$ (14). According to published results, the administration of plerixafor in patients with germ cell tumors achieved a successful mobilization rate in $86 \%$ of the cases, with $50 \%$ of the patients subsequently undergoing high-dose chemotherapy with AHSCT and presenting an average of $2.6 \times 10^{6} \mathrm{CD} 34^{+}$cells $/ \mathrm{kg}(7)$. In our case series, $80 \%$ of the patients reached this $\mathrm{CD} 34^{+}$count and were able to undergo subsequent treatment.

At a time when the benefit/cost ratio of drugs is a major issue due to the restriction of economic resources, several options are available for patients exhibiting poor HSC mobilization, including additional days of mobilization, a second attempt with G-CSF and the use of chemotherapy followed by the mobilization or the extraction of stem cells from the bone marrow. In this context, apart from the cost, the emotional burden of repeated HSC mobilization failures in patients with cancer should also be taken into consideration. Since plerixafor was first used in clinical practice, it has been administered to patients in these same procedural ways (15-17), proving to 
be cost-effective through reducing the number of apheresis sessions and the number of failed mobilization attempts (18). However, our patient sample was very limited. Therefore, further investigation regarding the use of plerixafor in patients with refractory germ cell tumors is required, in order to increase our understanding of the activity of this drug in this setting.

In conclusion, plerixafor is likely to be an effective and safe drug for the treatment of patients with high-risk germ cell tumors who are candidates for AHSCT but have failed prior mobilization with G-CSF. These patients may benefit from plerixafor, similar to patients with lymphoma and multiple myeloma.

\section{Acknowledgements}

The authors wish to thank Sanofi Spain for their financial support in the form of grants, equipment and drugs.

\section{References}

1. Agarwala AK, Perkins SM, Abonour R, Brames MJ and Einhorn LH: Salvage chemotherapy with high-dose carboplatin and etoposide with peripheral blood stem cell transplant in patients with relapsed pure seminoma. Am J Clin Oncol 34: 286-288, 2011.

2. Einhorn LH, Williams SD, Chamness A, Brames MJ, Perkins SM and Abonour R: High-dose chemotherapy and stem-cell rescue for metastatic germ-cell tumors. N Engl J Med 357: 340-348, 2007.

3. Kondagunta GV, Bacik J, Sheinfeld J, et al: Paclitaxel plus ifosfamide followed by high-dose carboplatin plus etoposide in previously treated germ cell tumors. J Clin Oncol 25: 85-90, 2007.

4. Voss MH, Feldman DR and Motzer RJ: High-dose chemotherapy and stem cell transplantation for advanced testicular cancer. Expert Rev Anticancer Ther 11: 1091-1103, 2011.

5. Horwitz ME, Chute JP, Gasparetto C, et al: Preemptive dosing of plerixafor given to poor stem cell mobilizers on day 5 of G-CSF administration. Bone Marrow Transplant 47: 1051-1055, 2012.

6. Saure C, Weigelt C, Schroeder T, et al: Plerixafor enables successful hematopoietic stem cell collection in an extensively pretreated patient with testicular cancer. Acta Haematol 124 235-238, 2010.
7. Kobold S, Isernhagen J, Hübel K, et al: Plerixafor is effective and safe for stem cell mobilization in heavily pretreated germ cell tumor patients. Bone Marrow Transplant 46: 1053-1056, 2011.

8. DiPersio JF, Micallef IN, Stiff PJ, et al: Phase III prospective randomized double-blind placebo-controlled trial of plerixafor plus granulocyte colony-stimulating factor compared with placebo plus granulocy te colony-stimulating factor for autologous stem-cell mobilization and transplantation for patients with non-Hodgkin's lymphoma. J Clin Oncol 27: 4767-4773, 2009.

9. DiPersio JF, Stadtmauer EA, Nademanee A, et al; 3102 Investigators: Plerixafor and G-CSF versus placebo and G-CSF to mobilize hematopoietic stem cells for autologous stem cell transplantation in patients with multiple myeloma. Blood 113: 5720-5726, 2009.

10. Maroto P, Garcí Del Muro X, Sastre J and Isla D: SEOM guidelines: non-seminomatous germ cell cancer (NSGCC). Clin Transl Oncol 13: 565-568, 2011.

11. Bokemeyer C, Harstrick A, Beyer J, et al: The use of dose-intensified chemotherapy in the treatment of metastatic nonseminomatous testicular germ cell tumors. German Testicular Cancer Study Group. Semin Oncol 25: 24-32; discussion 45-28, 1998.

12. Lorch A, Mollevi C, Kramar A, et al: Conventional-dose versus high-dose chemotherapy in relapsed or refractory male germ-cell tumors: A retrospective study in 1,594 patients. J Clin Oncol (ASCO Meeting Abstracts) 28: 4513, 2010.

13. Beyer J, Kingreen D, Krause M, et al: Long-term survival of patients with recurrent or refractory germ cell tumors after high dose chemotherapy. Cancer 79: 161-168, 1997.

14. Tricot G, Cottler-Fox MH and Calandra G: Safety and efficacy assessment of plerixafor in patients with multiple myeloma proven or predicted to be poor mobilizers, including assessment of tumor cell mobilization. Bone Marrow Transplant 45: 63-68, 2010.

15. Basak GW, Mikala G, Koristek Z, et al: Plerixafor to rescue failing chemotherapy-based stem cell mobilization: it's not too late. Leuk Lymphoma 52: 1711-1719, 2011.

16. Costa LJ, Alexander ET, Hogan KR, Schaub C, Fouts TV and Stuart RK: Development and validation of a decision-making algorithm to guide the use of plerixafor for autologous hematopoietic stem cell mobilization. Bone Marrow Transplant 46: 64-69, 2011.

17. Li J, Hamilton E, Vaughn L, et al: Effectiveness and cost analysis of 'just-in-time' salvage plerixafor administration in autologous transplant patients with poor stem cell mobilization kinetics. Transfusion 51: 2175-2182, 2011.

18. Shaughnessy P, Islas-Ohlmayer M, Murphy J, et al: Cost and clinical analysis of autologous hematopoietic stem cell mobilization with G-CSF and plerixafor compared to G-CSF and cyclophosphamide. Biol Blood Marrow Transplant 17: 729-736, 2011. 